\title{
MISSING THE POINT? \\ FINDING CONTEXTUAL DETAIL IN ENTREPRENEURSHIP AND SMALL FIRM SCHOLARSHIP
}

\author{
DOMINIC M. CHALMERS \\ Strathclyde Business School \\ University of Strathclyde \\ Glasgow, G4 0GE \\ ELEANOR SHAW \\ Strathclyde Business School
}

\begin{abstract}
Entrepreneurship scholarship can be characterized by a trend towards functionalism. This has arguably led to findings that trade the contextualization of entrepreneurial processes for abstract generalizations. A methodological response is proposed that draws on ethnomethodology and conversation analysis to form the basis of a more nuanced conception of the entrepreneur.
\end{abstract}

\section{INTRODUCTION}

"Water, water, everywhere,

And all the boards did shrink;

Water, water, everywhere,

Nor any drop to drink."

\section{Rime of the Ancient Mariner, Samuel Taylor Coleridge}

Coleridge's passage is a fitting analogy for entrepreneurship and small firm (Entre/SME) scholarship in which context is, at once, everywhere, yet nowhere in the analytical spotlight. One factor behind the prevailing 'soft-focus' approach to context is philosophical and methodological choice; as Jennings, Perren, and Carter (2005) note, Entre/SME research exists within a functionalist hegemony that relegates alternative analytical paradigms to either peripheral - or worse - deviant roles. The effect of this positivistic trajectory on our understanding of The Entrepreneur is significant. Scholars can, in practice, formulate research problems theoretically without ever entering the field and in doing so risk both the contextual relevance of their findings and the reification of core constructs. Interpretative research, which has gradually achieved some degree of legitimacy in the international field, is notionally better connected to the "lived world'. However, ongoing pressures to generalize and decontextualize findings using multiplecase study approaches have arguably led to similar problems of abstraction.

This article will explore the treatment of context and practice in the entrepreneurship domain before suggesting an alternative philosophical and methodological direction for scholars seeking to connect with the situated 'work' of the entrepreneur. We begin by reviewing recent debates concerning the institutionalization of logico-positivistic approaches in entrepreneurship 
research before considering calls to explore entrepreneurial phenomena from beyond present ontological and epistemological boundaries (Down, 2013; Watson, 2013). We then turn to the analytical significance of both context and practice, each of which are important features of research whose relative prominence is, to a large extent, contingent on philosophical and methodological choice. Recent articles by Welter (2011) and others (Fletcher, 2011; Watson, 2013) have reopened discussions around the significance of context and there is now a welcome move towards 'theorizing context' rather than simply contextualizing theory (although both are important considerations for researchers). Finally, a framework drawing on Erving Goffman's interaction order $(1955,1961)$, Harold Garfinkel's Ethnomethodology (1967) and Harvey Sacks' Conversation Analysis (Sacks \& Jefferson, 1995) is presented that undertakes to prioritize the practical knowledge of the entrepreneur and their accountability and orientation towards contextual factors. This research approach avoids the "arbitrary invocation of a countless number of extrinsic, potential aspects of context" (Arminen, 2005: XV); a problem scholars often encounter when framing their analyses. The paper concludes by discussing some of the challenges and rewards that may be encountered through the adoption of sociological and linguistic approaches to entrepreneurship scholarship.

\section{(RE)CONCEPTUALISING THE SITUATED NATURE OF ENTRPERENEURIAL PROCESSES}

An area of investigation that has been conspicuously absent from Entre/SME scholarship concerns the practical 'doing' (Anderson, Dodd, \& Jack, 2012) - or, the 'work' - of being an entrepreneur in a specific context. As scholars, we know surprisingly little about how entrepreneurs accomplish mundane activities through everyday social interactions, or how they navigate routine business problems within locally embedded social, cultural and institutional contexts. Experience shows this is not a problem that is necessarily unique to entrepreneurship; Llewellyn and Hindmarsh (2010) make a similar observation within the field of organizational studies where, "in research papers, what some domain of work practically entails is normally covered in a section before the analysis begins" (4). So, to briefly return to the Coleridge analogy that opened this paper, descriptions of practice in entrepreneurship research seem to be everywhere - much like water - yet they remain stubbornly beyond analytical reach. Rarely are scholars seizing the valuable insights open to them by putting practice and context fully under the microscope. This is a notion supported by Moroz and Hindle (2012) in their review of process-based theories of entrepreneurship which reveals that only 9 of 32 models considered are empirically derived. From an analytical perspective this is problematic; the everyday, often mundane, activities people do to get their work done constitute the foundations of social order and institutions (Miettinen, Samra-Fredericks, \& Yanow, 2009). Failing to engage with these building blocks from an appropriate philosophical or theoretical perspective increases the chasm between research findings and lived reality, in turn diminishing the likely explanatory and predictive power of emergent theory. In sum, this aloofness from practice may continue to frustrate efforts to understand the how of entrepreneurship and could negatively affect the practical utility of entrepreneurship research for both practicing entrepreneurs and policymakers. There is a need therefore to study "phenomena that are actually done, as they become evident in the here and now" (Miettinen et al., 2009: 1309), and to adopt methodological resources that will facilitate this new programme of research. 


\section{Making the Case for a Contextualized Approach}

Before progressing further it is worth briefly considering why context is important, and for that matter why it should be given a more prominent role in entrepreneurship scholarship. The most obvious response is that conventional sociology, in the mode of Durkheim, considers that context enables and constrains social actions. Therefore, without cognizance of the extrinsic social 'facts' that exist independent of the individual, entrepreneurial behavior cannot be fully accounted for. While psychology - from which the field of entrepreneurship draws liberally - is considered to be the science of the individual, sociology is the science of society and arguably therefore requires an increased sensitivity to micro and macro-contextual factors. Holmquist (2003) identifies a scholarly fixation with the entrepreneurial individual, warning that, "aspects of entrepreneurial action have to be analyzed in their specific context to grasp the full meaning of the studied phenomenon" (84). This preoccupation has in turn contributed to "frustrated efforts to overgeneralize results across very heterogeneous settings within and across studies" (Wiklund, Davidsson, Audretsch, \& Karlsson, 2011: 4).

Scholars are increasingly recognizing that sections of entrepreneurship research have failed to adequately account for context in a theoretical and empirical manner (Morrison, 2006; Ucbasaran, Westhead, \& Wright, 2001; Welter, 2011; Zahra, 2007). Zahra (2007) identifies ongoing tensions between the theorization and contextualization of research by explicating difficulties inherent in utilizing 'borrowed' models that are grounded in assumptions often reflecting other phenomena. Context, defined by Welter (2011: 167) within a management research framework as "circumstances, conditions, situations, or environments that are external to the respective phenomenon and enable or constrain it", operates concomitantly across a multiplicity of dimensions, yet despite this, entrepreneurship papers tend to focus on only a single aspect of context (Holmquist, 2003; Welter, 2011). Leitch, Hill, and Harrison (2010) and Bygrave (2007) blame the tendency of entrepreneurship scholars to ape the reductionist natural sciences for poor contextualization, while Gartner (2010) argues that quantitative studies, which are proportionally overrepresented in top entrepreneurship journals, "can never portray the interdependent interactive aspects of individuals over time, engaging with, and responding to, their circumstances"(10).

The call from many scholars who seek to rebalance entrepreneurship scholarship on a more contextualized and anti-positivistic keel, has been to explore interpretivist epistemologies. Yet, these too present some methodological problems for the development of the research field. Take for instance ethnography and associated approaches such as autoethnography (Fletcher, 2011), action research and participant observation (Mueller, Volery, \& von Siemens, 2012). This loose family of methods is grounded in painstaking fieldwork and provides richly descriptive insider accounts of often poorly understood phenomena (e.g., Bruni, Gherardi, \& Poggio, 2004). From a context perspective though, these approaches are somewhat problematic; the researcher has an infinitesimal number of contexts that can be selected to frame their research findings and therefore, as a consequence, the 'knowledgability' of the researcher, which is mostly derived from reconstructed post-hoc field notes, is prioritized over the data subject.

Consider the following passage of illustrative 'contextual' information provided by Welter (2011: 166):

"In rural post Soviet Uzbekistan young women and girls are supposed to stay home until they are married. Therefore, the young woman learned a traditional craft because this was one of 
the few vocational training opportunities available to her; and this activity could be conducted from home."

Several potentially important contextual factors are identified in this short passage. We know that this research is based in (1) rural (2) post Soviet Uzbekistan in a possibly paternalistic society where (3) women and girls are supposed to stay at home until they are married.

Furthermore, an unsophisticated economy is alluded to as the girl learned a (4) traditional craft as there are (5) few vocational training opportunities available. Finally, religious constrictions are perhaps implied by the significance of the work activity being (6) conducted from home. While all of these factors (gender, race, age, religion and social status) are hypothetically relevant for explaining the enacted phenomenon of female entrepreneurship in this particular time and place, they nevertheless represent analytical layers that the researcher has deemed important (perhaps through a prioi theorizing or even personal or experiential preference). So, while the ethnographic approach will certainly provide invaluable description of a phenomenon within a given context, it does not necessarily present satisfactory evidence that these were the relevant contextual forces that enabled or constrained the data subjects' social actions.

\section{Interaction Order, Ethnomethodology and Conversation Analysis}

Conversation Analysis (CA), developed by Harvey Sacks in the 1960's, is the systematic analysis of talk-in-interaction. The purpose of such analysis is to uncover the intersubjective meaning of social actions by subjecting recordings of naturally occurring interaction to exhaustive scrutiny. Sacks and others (Sacks \& Jefferson, 1995; Sacks, Schegloff, \& Jefferson, 1974) constructed a framework on the foundational efforts of Erving Goffman $(1955,1961)$ whose own pioneering interest in face to face 'interaction order', inspired Harold Garfinkel's $(1967 ; 1974)$ ethnomethodological approach. Ethnomethodology is the study of participants' methods for achieving endogenous social order in a given context. It remains a somewhat radical social theory owing to a rejection of 'micro' or 'macro' explanations for social action.

This emphasis on the 'detail' of social action forms the basis of ethnomethodologically informed studies' unique contribution to social science. Garfinkel himself offers strong criticism $(1948 / 2006,1952 / 2008)$ of sociological approaches that he believes obscure what individuals actually $d o$, insisting instead that order can be obtained from even the most mundane examples of interaction. This in turn forms the basis for conversation analysis and Harvey Sack's often repeated mantra of 'order at all points'. Conversation analysis, or ethnomethodological interaction analysis as some believe is should be more accurately titled (Psathas, 1995), is a rigorous set of principles and procedures for studying the social world as it happens.

\section{Abandoning the Bucket Approach to Context}

Central to an ethnomethodological/conversation analysis mentality is a rejection of what Garfinkel (1967) terms the 'bucket approach' to context whereby actors are treated as 'cultural dopes'. This is a terms that refers to "man-in-the-sociologist's-society who produces the stable features of the society by acting in compliance with preestablished and legitimate alternatives of action that the common culture provides" $(1967, \mathrm{p} .68)$. The implication of this position is that the entrepreneur, or any other social actor for that matter, is treated as a passive puppet of "abstract social forces which impose themselves on participants" (Hutchby \& Wooffitt, 2008: 139). Conversation analysis takes a contrasting perspective, holding that individuals are actively 
knowledgeable of their environment, making visible (to others, and hence analysts) their orientation "to the relevance of contexts"(ibid). Each utterance or gesture made in response to a prior interlocutor's utterance provides evidence of how intersubjective understanding of a task or activity is maintained. Analyst's must therefore 'bracket' understanding of context in order to grasp the endogenous construction of structure through this interaction (Arminen, 2005).

\section{Talk as Doubly Contextual}

A fundamental departure point for studies of CA is the notion that talk and actions are doubly contextual. In this sense context is considered to include both the "immediately local configuration of preceding activity in which an utterance occurs, and also to the "larger" environment of activity within which that configuration is recognized to occur" (Drew \& Heritage, 1992: 18). Firstly, talk is context shaped in that it cannot be understood without reference to the preceding utterance. The context will also enable and constrain episodes of talk meaning that participants in an interaction must design their behavior in a manner appropriate to the local environment. This becomes particularly important during formal and quasi-formal institutional interactions such as courtrooms, classrooms or even news interviews. In the latter example, news journalists must design their talk by taking into consideration obligations of 'neutrality' and 'objectivity' when conducting live interviews on-air (Clayman \& Heritage, 2002; Greatbatch, 1998). Close analysis of these interactions can provide description of how 'neutrality' is achieved (and often circumvented) by reporters.

Second, talk is context renewing. As "every current utterance will itself form the immediate context for some next action in a sequence, it will inevitably contribute to the contextual framework in terms of which the next action will be understood (Drew \& Heritage, 1992: 18). This means that interactional context is a dynamic and changeable structure that is perpetually being renewed, maintained and altered in increments. This provides justification for a rejection of a 'containing view' of structure where 'cultural dopes' are at the mercy of abstract social forces. Instead, it demonstrates that context is endogenously created by knowledgeable actors who make visible their orientation to context and hence sustain intersubjectivity. This mind-set signals a possible intersection with Steyaert's (2007) conception of 'entrepreneuring' in which entrepreneurial identity is an ongoing project rather than a final product of activity. Similarly, it acknowledges Sarasvathy's $(2001,2003)$ anti-deterministic theory of effectuation and Weick's $(1988,1995)$ organizational sensemaking.

\section{A RESEARCH AGENDA FOR AN OBSERVATIONAL SCIENCE OF ENTREPRENEURSHIP}

Considerable strides have been taken in pushing entrepreneurship scholarship towards pathways that embrace pluralist epistemologies and ontologies (Anderson \& Warren, 2011; Sarasvathy \& Venkataraman, 2011; Wiklund et al., 2011). It is argued however that there remain many theoretical resources from the disciplines of sociology and linguistics that could be applied to gain a better understanding of "when, how and why entrepreneurship happens" (Welter, 2011: 176). As our article has illustrated, this may require a significant shift in the mental models of both researchers and users of entrepreneurship research. This is rarely a painless endeavor; Silverman (1998: vii) recalls a noted academic from the London School of Economics "noisily walking out in disgust from the hall during Sack's talk" at a 1972 conference on 
ethnomethodology and symbolic interactionism. It does - at least initially - seem heretical to abandon a container theory of context in which pre-established extrinsic social structures enable and constrain individual behavior. CA however offers a particularly robust alternative to this position that - uniquely amongst methods - provides concrete empirical explanation as to how individuals accomplish intersubjective order within a given context. While CA research may not offer superficially attractive general theories, it does afford the potential to cut across some of the static that envelops emerging research paradigms such as entrepreneurship, by reconnecting abstract theoretical models with examples of practice.

When Sarasvathy and Venkataraman (2011) ask the fundamental question, 'what do entrepreneurs do', they focus their answer, as most scholars do, on categories of activity such as seeking opportunities or creating organizations. From a conversation analysis, or even a more general practice-oriented perspective, this does not, in actual fact, explain what entrepreneurs $d o$. What does exploiting an opportunity look like in practice rather than as a reified construct? How do entrepreneurs rebalance relational asymmetries during interactions with venture capitalists? How do they accomplish the act of a single networking encounter? Or a selling encounter? Or a business negotiation? Or even a collaborative strategizing activity for that matter? How can it be empirically shown that certain contextual factors are relevant for accomplishing these activities while others are not? These are questions that we propose can be answered through real time analysis of naturally occurring scenes of entrepreneurship using ethnomethodological and conversation analysis methodologies.

It is no stretch to say that entrepreneurship happens through interaction (Chell, 2007). From informal interaction with venture employees, family members, suppliers, customers and competitors through to quasi-formal and even formal interactions with bank managers, venture capitalists, newspapers, conference audiences and business incubators. Where these interactions have been studied, very few have taken seriously the actual 'work' involved in creating and sustaining local mutually intelligible order. Instead, social actions are read against a priori themes and categories that look, and expect to find certain behaviors and actions. Our intention with this article is to offer a departure point for entrepreneurship scholars seeking to understand the institutional and contextual character of everyday social interaction. Pursuing this objective using the methodological resources of conversation analysis and ethnomethodology will, we hope, help to create a truly observational science of entrepreneurship.

\section{REFERENCES AVAILABLE FROM THE AUTHORS}

